\title{
O PIBID e sua contribuição na formação dos acadêmicos de Licenciatura em Química da Universidade Estadual de Roraima
}

\author{
Eusani Silva Sousa, Iury José Sodré Medeiros \& Ivanise Maria Rizzatti
}

Universidade Estadual de Roraima (UERR). Campus Boa Vista, Curso de Licenciatura em Química. Rua Sete de Setembro 231, Canarinho CEP 69306-530C, Boa Vista, Roraima, Brasil.

*E-mail para correspondência: niserizzatti@gmail.com

Recebido em: 23 de agosto de 2016. Aceito em: 13 de março de 2017. Publicado PDF em: 16 de março de 2017

\section{RESUMO}

\begin{abstract}
O PIBID e sua contribuição na formação dos acadêmicos de Licenciatura em Química da Universidade Estadual de Roraima. Este trabalho buscou identificar as concepções de alunos das duas primeiras turmas do curso de Licenciatura em Química da Universidade Estadual de Roraima, campus Boa Vista, sobre programas voltados para melhorar e incentivar a formação docente. Os alunos da $1^{\text {a }}$ turma não participaram de ações do Programa Institucional de Bolsas de Iniciação à Docência (PIBID) ou outro programa como motivadores para seguir a carreira docente, enquanto que a $2^{\mathrm{a}}$ turma participou desses programas. A pesquisa de caráter qualitativo incluiu análise de respostas a um questionário avaliadas de acordo com os métodos de Análise de Conteúdo. Os resultados indicaram que os objetivos do programa estão sendo parcialmente atingidos e indicam, também, alguns problemas na formação docente do grupo de alunos não participantes do PIBID ou outro programa durante a sua graduação.
\end{abstract}

PALAVRAS CHAVE: PIBID; Formação docente; Ensino de Química.

\section{ABSTRACT}

The PIBID and its contribution in the training of undergraduate students in Chemistry of the State University of Roraima. This study aimed to identify the conceptions of students of the first two classes of the first degree in chemistry from the State University of the Roraima, Boa Vista, about programs designed to improve and promote teacher training. Students of the 1st group did not participate in actions of the Institutional Scholarship Program Introduction to Teaching (PIBID) or another program as motivators to follow a teaching career, while the 2 nd class participated in these programs. The qualitative research included analysis of responses to a questionnaire, assessed according to the content analysis methods. The results indicated that the program objectives are partially achieved and also indicate some problems in teacher training the group of non-participating students PIBID or another program during their graduation.

KEY WORDS: PIBID, teacher training; Chemistry teaching .

\section{INTRODUÇÃO}

O Programa Institucional de Bolsas de Iniciação à Docência (PIBID) tem demonstrado a sua contribuição na formação dos estudantes das licenciaturas na medida em que vem aumentando a relação existente entre a formação teórica e prática experimental na área de Ensino de Química, já que logo no início da graduação, os acadêmicos entram em contato direto com a sala de aula, observando a ausência de experimentos que ajudam na facilitação da aprendizagem em química nas escolas públicas. Desta forma, o PIBID tem colaborado substancialmente com a permanência desses alunos nos cursos de licenciatura, desenvolvendo a qualificação destes profissionais.

O Programa é uma proposta da Coordenação de Aperfeiçoamento de Pessoal de Nível Superior (CAPES) do Ministério da Educação, executado pela a CAPES, com o apoio Fundo Nacional de Desenvolvimento da Educação (FNDE). O projeto apresenta-se como ferramenta metodológica atraente, que por meio das pesquisas exercidas pelos alunos, com a orientação do professor contribui para que o professor seja um "ser social" que está imerso no seu tempo e espaço. Sendo assim, entende-se que no processo ensino-aprendizagem existem 
diversas alternativas metodológicas, ou seja, o professor em parceria com o estudante devem buscar estas possibilidades.

Tratando especificamente da área de Licenciatura em Química, e partindo da compreensão de que o conhecimento de química é fundamental para que o indivíduo possa estar conectado com a sociedade, que tem se tornado cada vez mais aberta às inovações tecnológicas, pelo fato de exigir do estudante a interpretação e a compreensão dos fenômenos químicos que lhe cerca. Cabe ao profissional de química, nos espaços escolares, possibilitar ao estudante a compreensão melhor desse universo que o cerca a cada dia.

Deste modo, a formação com qualidade de professores é de suma importância para que o ensino de química não passe por questionamentos devido a um modelo predominantemente tecnicista. O Ensino de Química tem como principal ferramenta o quadro branco e o pincel, sendo um método pouco eficiente para a contextualização no ensino, pelo fato desta temática ser altamente abstrata levando o aluno há uma desmotivação no processo de ensino e aprendizagem. Segundo Echeverría \& Zanon $(2010$, p.30) a formação do professor no Brasil esta arraigada a um sistema de memorização sem uma formação crítica, sendo altamente descontextualizada com a realidade na qual o aluno esta inserido.

O Ensino de Química deve ser tratado como uma ferramenta que possibilita uma melhor formação do cidadão, pois é necessário que os cidadãos tenham em mente que a química faz parte do seu dia a dia. Santos \& Schnetzler (2010, p.49) afirmam que:

A química no ensino médio não pode ser
ensinada como um fim em si mesma, senão
estaremos fugindo do fim maior da Educação
Básica, que é assegurar ao indivíduo a formação
que o habilitará a participar como cidadão na
vida em sociedade. Isso implica um ensino
contextualizado, no qual o foco seja o preparo
para o exercício consciente da cidadania.

Mas em muitas escolas públicas brasileiras ou até mesmo privadas não há motivação do intelecto dos estudantes, não é raro que em escolas públicas os professores passem boa parte do tempo copiando uma lição na lousa, desperdiçando os minutos preciosos da disciplina e ministrando aulas somente com um livro didático, sendo este método caracterizado como arcaico, logo não contribuindo para facilitação do ensino de química, desta forma, constata-se o despreparo destes profissionais.

$\mathrm{O}$ professor como profissional atuante $\mathrm{e}$ mediador do conhecimento deve estar em contato direto com o estudante, buscando alternativas que possam levar a uma mudança de visão deste estudante em relação ao ensino da Química. Uma vez que muitos autores discutem que o grande desinteresse dos estudantes pela disciplina de química, deve-se, em geral, pela falta de atividades experimentais que possam relacionar a teoria à prática (Guimarães 2009; Rosa 2012; Pauletti 2012; Lima 2012; Maldaner 2013).

O curso de Licenciatura em Química da Universidade Estadual de Roraima desenvolve o PIBID desde agosto de 2011 com o objetivo de capacitar os graduandos para o uso da experimentação no ensino de química, aproximando o acadêmico com a realidade e desafios do futuro campo profissional, com a ideia de torná-lo um professor inovador e criativo, para vencer os desafios do dia-a-dia encontrados em sala de aula.

As práticas experimentais atuam como mediadoras na construção cognitiva do conhecimento científico e estimulam o caráter investigativo do indivíduo. De acordo com essa perspectiva, introduzir a Química no cotidiano escolar dos alunos por meio de atividades práticas pode ser uma forma eficaz no processo de ensino-aprendizagem.

Uma reflexão sobre o ensino de Química e as dificuldades encontradas por parte dos acadêmicos de licenciatura em química em assimilar e consequentemente repassar os conceitos abstratos exigidos pela mesma, possibilita uma análise sobre a importância e a validade de aulas práticas para uma aprendizagem mais significativa mediada pelo PIBID.

Este trabalho tem como objetivo avaliar e identificar as concepções de alunos de duas turmas do curso de Licenciatura em Química da Universidade Estadual de Roraima sobre o programa PIBID, enquanto ferramenta complementar na formação docente.

\section{MATERIAL E MÉTODOS}

$\mathrm{Na}$ investigação procurou-se saber o que pensam os graduados e licenciandos das $1^{\circ}$ e $2^{\circ}$ 
turmas da UERR, respectivamente, sobre o PIBID enquanto ferramenta complementar na formação dos estudantes de Licenciatura em Química da Universidade Estadual de Roraima, numa perspectiva reflexiva. Esta investigação foi desenvolvida pelo método de pesquisa qualitativa, na qual foi utilizada como instrumento a modalidade questionário e observações diretas durante as atividades do PIBID/UERR/subprojeto Química no ano de 2013. A pesquisa qualitativa faz parte de uma metodologia de pesquisa que não obedece a roteiros definidos rigorosamente e são baseados em pequenas amostras.

$\mathrm{O}$ instrumento utilizado - questionário - foi elaborado com questões abertas abordando referentes ao PIBID como ferramenta complementar na formação acadêmica. Assim, foi aplicado um questionário com cinco perguntas abertas aos alunos que não participaram do programa PIBID/UERR/ Química, neste caso os egressos, e outro questionário com sete perguntas abertas para 10 alunos participantes do PIBID iniciados em agosto de 2011. Para discussão dos resultados adotaremos como nomenclatura Turma A para os egressos, e Turma B para os licenciandos bolsistas PIBID.

As questões para os graduados estavam voltadas sobre as deficiências do curso de Licenciatura em Química para sua formação enquanto professor de química, por exemplo, se eles participaram de algum programa ou projeto científico ou tecnológico durante a sua graduação, se conheciam o PIBID, entre outras. Para os acadêmicos foi perguntado se conheciam o PIBID, se este programa contribui para a formação docente em química, se as ações do PIBID o motivavam a seguir a carreira docente, entre outras.

\section{RESULTADOS E DISCUSSÃO}

Os sujeitos da pesquisa foram graduados (Turma A) e licenciandos (Turma B) das duas primeiras turmas de química da UERR, campus Boa Vista. Foram enviados 20 questionários para as duas turmas, mas somente 11 colaboraram até a conclusão da pesquisa.

A seguir, são apresentados os resultados do processo de análise e interpretação dos dados obtidos por meio das respostas fornecidas pelos sete alunos da Turma A e quatro alunos bolsistas do PIBID/UERR/Química 2011 (Turma B), e os dados foram organizados da seguinte forma, primeiro são apresentadas as perguntas e depois as respostas.

\section{Análise do Questionário A - Turma A}

$\mathrm{Na}$ primeira questão fora solicitado aos graduados que indicassem quais as deficiências do curso de Licenciatura em Química para sua formação enquanto professor de química. Nessa categoria, consideramos as respostas dos alunos que fazem referência às deficiências deixadas durante a graduação e têm por finalidade discutir o modelo tradicional de formação dos cursos de Licenciatura que conferem uma visão simplista à atividade docente, tornando esse processo pouco eficiente em sua função formativa. Sendo este modelo caracterizado pela dicotomia teoriaprática e pela falta de integração disciplinar pautado na ideia da transmissão/recepção.

Neste sentido, os graduados relataram que as deficiências foram professores descompromissados em desempenhar o papel de educador e ausência de aulas práticas no laboratório.

Em relação à participação em algum programa, projeto científico ou tecnológico durante a graduação, $100 \%$ dos egressos responderam que não participaram de nenhum programa de incentivo a docência, quando estavam na universidade. Uma vez que o ensino consiste em um fenômeno social e não apenas metodológico, é importante a reflexão do professor sobre os fins e os valores que envolvem a docência, a fím de que possa se situar diante dessa profissão e atuar plenamente em sua área (Arroio et al. 2008).

Perguntou-se também aos graduados se conheciam o Programa Institucional de Bolsa de Iniciação à Docência (PIBID), e apenas um dos respondentes disse que não conhecia o PIBID, enquanto quatro disseram ter conhecimento sobre o PIBID, mas não tiveram o mesmo na sua formação acadêmica como incentivo para aperfeiçoar sua carreira profissional. Dois estudantes relataram que "Sim, um projeto de estágio onde participam alunos matriculados na Universidade Estadual, os alunos selecionados prestam estágio remunerados em empresas conveniadas com a instituição"; "Conheço. O PIBID é um exemplo claro de incentivo aos alunos bolsistas e não bolsistas, que estão cursando química vale a pena dedicar-se no curso e participar desse tipo de projeto". 
Esse programa é um incentivo a docência nos cursos de Licenciatura, os acadêmicos tem o contato direto com os alunos da rede pública de ensino, trabalhando teoria/prática em sala de aula, podendo, assim, contribuir para melhorar o índice do Índice de Desenvolvimento da Educação Básica (IDEB) no estado.

Perguntou-se também se o PIBID ou outro programa que aproxima escola e universidade contribui para a formação docente em química, e todos os respondentes afirmaram que sim. Um destes respondentes complementou "Não tive a oportunidade de participar deste programa, mas acredito que o mesmo pode contribuir na formação dos acadêmicos, pois oferecem oportunidades de exercer a profissão e conhecer a realidade das escolas do nosso estado"; e outro relatou que "O PIBID ou outro programa proporciona sim essa integração, pois o acadêmico vivenciar prática/teoria em contato direto com os alunos, buscando aprimorar seus conhecimentos, desenvolvendo projetos e obtendo experiências para sua carreira docente".

A penúltima questão abordou se a ação do PIBID ou outro programa poderia motiva-los a seguir a carreira docente, e três respondentes afirmaram que não. "Não diretamente, pois o PIBID não existia antes de 2007 e muitos profissionais que terminaram sua graduação antes desta data são ótimos profissionais motivados". Quatro disseram que sim. "Com certeza, seja de qual for à espécie, ou seja, programas, projetos, encontros, congressos, bolsas de estudos, sempre servem como incentivo para alcançar o objetivo do acadêmico, pois assim poderá estar em contato com outras realidades e poderá compartilhar e obter conhecimentos distintos a sua realidade, e assim desenvolver trabalhos em prol da sua comunidade".

"Não exerço a profissão, mas ainda tenho esperança de lecionar. $E$ com certeza o desenvolvimento de projetos durante a fase acadêmica contribui muito no ensino $e$ aprendizagem de todos, e facilitar a troca de experiências dos acadêmicos durantes os estágios, pois muitos de nós apresentaram bastantes dificuldades durante a Prática profissional".

Programas que proporcionam aos futuros professores uma formação inicial com vivências em diferentes experiências metodológicas estabelecidas, tais como: oficinas temáticas, experimentação investigativa, temas geradores, três momentos pedagógicos, temas estruturadores, interdisciplinaridade (Braibante \& Wolmann 2012), certamente podem promover uma mudança de cultura na formação de professores, incentivando a profissão docente.

Nos últimos anos, tem-se debatido muito sobre a formação inicial dos professores. Maldaner (2013) aponta para questões relacionadas a como se produz e como se desenvolve o conhecimento nos modelos de formação. Essas questões têm ocupado debates em todos os âmbitos, mobilizando pesquisadores, professores formadores e políticos envolvidos com o campo da educação, reconhecendo o papel central do professor em qualquer processo de mudança no contexto educativo (Silva \& Martins 2014).

\section{Análise do Questionário B - Turma B}

$\mathrm{Na}$ primeira questão solicitou que aos licenciandos que comentassem sobre o que conheciam do Programa Institucional de Bolsa de Iniciação à Docência (PIBID). Os estudantes comentaram que o PIBID é um projeto que objetiva proporcionar os licenciados a oportunidade de estarem vivenciando no seu dia a dia a experiência docente, trabalhando projetos para melhorar sua formação e também o ensino em escolas públicas, contribuindo para um aprendizado significativo de cada aluno dessas escolas.

Nessa direção, o PIBID constitui um programa de política pública que objetiva, entre outros aspectos, contribuir com a formação de futuros docentes, promovendo o diálogo cooperativo com professores em exercício, enfatizando a escola como espaço formativo para que possam desenvolver e aplicar diferentes estratégias de ensino (Clímaco et al. 2012).

A segunda questão buscou saber se o PIBID contribui para a formação docente em Química, e todos foram unânimes em afirmar que sim. Segundo os respondentes o programa oferece oportunidade para os alunos da rede pública estudarem teoria e prática, melhorando e elevando seu grau de conhecimento.

"Através do PIBID, os acadêmicos vivenciam a realidade que acontece dentro das escolas, $e$ os mesmos contribuem com o aprendizado dos estudantes, pois essa interação que ocorre entre os alunos das escolas públicas com os acadêmicos 
integrantes do projeto PIBIB de química da UERR prepara os acadêmicos para futuramente exercer melhor seu papel de professor em sala de aula".

Com o PIBID, percebe-se, segundo os professores do curso, que os acadêmicos da $2^{\mathrm{a}}$ turma de química da UERR, apresentaram melhor desempenho no processo de ensino e aprendizagem, em relação a turma anterior, sendo seu curso melhor avaliado e valorizado, pois hoje com esse programa eles têm foco em sua formação profissional.

Perguntou-se também aos estudantes se a ação do PIBID os motiva para a carreira docente, e todos responderam que sim. Para eles é gratificante ensinar aos alunos os conteúdos já estudados durante o curso de graduação em Química, e ver o quanto eles se interessam e tiram suas dúvidas nas aulas, ademais os experimentais passaram a ser uma realidade nas aulas de química da escola atendida pelos bolsistas.

Nesse sentido, Santos (2007, p.2) afirma que:

[...] promover a educação científica e tecnológica dos cidadãos, auxiliando o aluno a construir conhecimentos, habilidades e valores necessários para tomar decisões responsáveis sobre questões de ciência e tecnologia na sociedade e atuar na solução de tais questões.

Buscou-se também saber o que estimulou o licenciando a participar do PIBID, e as seguintes respostas foram obtidas: "Saber que através do PIBID temos a oportunidades de vivenciar diretamente situações que sem o mesmo, só poderiam ocorrer nos estágios supervisionados. Tendo a oportunidade de interagir diretamente com alunos fazendo essa troca de conhecimento, nos torna mais seguros e capazes de seguir essa carreira árdua que é a de educar"; "Primeiro a vontade de ter o contato diretamente com alunos, como também fazer parte de um trabalho que ajude a melhorar o ensino" e "A pesquisa $e$ experimentos com materiais alternativos".

Existe uma integração entre universidade e escola que proporciona aos universitários das licenciaturas participarem de experiências e de práticas pedagógicas, tendo a oportunidade de atuarem efetivamente junto aos alunos, incentivando as escolas públicas a tornarem-se protagonistas nos processos formativos dos estudantes das licenciaturas que nelas atuam.
Nesta direção, perguntou aos bolsistas se o PIBID promove a integração entre a UERR e a escola, e em caso afirmativo, solicitou-se que descrevessem como ocorre essa integração.

Todos acadêmicos concordam que o PIBID integra o elo entre essas duas instituições de ensino, desenvolvendo atividades tanto na UERR, quanto nas escolas.

Como foi mencionado pelos estudantes, o PIBID promove a integração da UERR com a comunidade. Além de aprimorar a formação dos acadêmicos, os quais tem a oportunidade de experimentar a iniciação à docência nas escolas públicas do estado de Roraima. O programa contribui também para a melhoria da qualidade da IES onde eles atuam e do próprio curso de licenciatura em Química da Universidade.

De acordo com os licenciandos o tempo dedicado ao projeto e as atividades são suficientes para a formação do futuro professor, somente um aluno acha que as atividades requerem mais tempo, "O tempo dedicado ao projeto sim, mais as atividades não, nos bolsistas poderíamos desenvolver um espaço ciências no final de semana iria ser bem gratificando tanto para os bolsistas como para os alunos".

$\mathrm{E}$, finalmente, pediu-se para os bolsistas comentarem sobre os objetivos do PIBID do curso de licenciatura de Química da UERR, e eles responderam:

"As nossas atividades desenvolvidas no PIBID têm sido bem aceito nas escolas, e isso tem sido uma referência para os nossos objetivos que é estimular o ensino de química através de atividades que o aluno presencia no seu dia-a-dia".

"O PIBID do curso de licenciatura em química da UERR, tem por objetivo levar através de acadêmicos Bolsistas, as escolas públicas da Capital e do Interior em Boa Vistal $R R$, a proposta de experimentos de forma simples no ensino de química, as aulas são elaborados por cada acadêmico, com kits de experimentos, utilizando-se materiais de baixo custo. Mais com o intuito maior de mostrar aos professores e alunos das escolas públicas que se pode dar uma aula experimental de química bem contextualizada, sem laboratório $e$ utilizando materiais alternativos. Pois com os experimentos os alunos ficam curiosos para saberem o que esta ocorrendo na determinada reação, e isso estimula o aluno a irem em busca de respostas, tornando os alunos mais 
críticos e interessados para aprenderem mais sobre o conteúdo de química".

Assim, ao elaborarem materiais e propostas didáticas utilizando diferentes abordagens e/ou enfoques, os licenciandos participantes desses subprojetos podem estudar a organização da aprendizagem (Paredes \& Guimarães 2012) como "uma construção de conhecimentos por parte dos alunos", não se tratando de "preparar algumas atividades, mas de desenhar o desenvolvimento dos temas à base de atividades a serem realizadas pelos alunos" (Carvalho \& Gil-Pérez 2000, p. 42).

Um dos coordenadores do PIBID/Química da UERR, avaliou o projeto PIBID como positivo. Segundo o mesmo: "Através do acompanhamento dos acadêmicos envolvidos no PIBID QUÍMICA nas diferentes atividades desenvolvidas a partir do segundo semestre de 2011 até a presente data, foi possivel avaliar positivamente o programa, principalmente quando se considera os seguintes aspectos: 1$O$ acadêmico é inserido na atividade docente por iniciativa própria sem ser obrigado a fazêlo como muitas vezes ocorre no momento do estágio obrigatório; 2- $O$ acadêmico é agente direto na escolha e elaboração das atividades experimentais, isso faz com que o mesmo tenha contato com os resultados mais atualizados da pesquisa científica em educação por meio dos artigos pesquisados; 3- $O$ acadêmico melhora sua desenvoltura e didática de forma mais natural do que nas disciplinas para esse mesmo fim; 4- A participação no PIBID ou em outros projetos de extensão elou pesquisa torna o acadêmico mais envolvido com a čultura universitária," ou seja, a vida acadêmica passa a ser vivenciada com maior intensidade, mais dedicação, maior permanência no ambiente universitário, resultando no melhoramento do desempenho geral. Enfim, ao longo desses anos de docência no ensino superior, mais especificamente na formação de professores, podemos fazer um paralelo entre aqueles professores formados antes do programa PIBID com os futuros professores que tiveram participação no programa. Ressalta-se que há um diferencial positivo bastante expressivo para aqueles que fazem parte do PIBID e/ou outros programas de extensão e pesquisa."

Desde o seu início, o PIBID tem se consolidado como uma iniciativa muito importante no que diz respeito à formação inicial dos acadêmicos das licenciaturas. Este vem preencher uma lacuna existente na maioria dos currículos dos cursos de Química Licenciatura, bem como nos órgãos de fomento para o desenvolvimento de projetos na área de Ensino (Braibante \& Womann 2012). Estes autores destacam que a possibilidade do conhecimento prévio do campo de atuação de educadores em formação e da integração entre os profissionais que atuam na escola e no ensino superior é o diferencial desse programa.

A experiência proporciona aos futuros professores uma efetiva reflexão sobre a prática docente, percebendo a necessidade de articular os eixos teoria e prática com a realidade contextual. Constatou-se que é preciso pensar e desenvolver metodologias que possibilitem a aprendizagem e o envolvimento dos alunos, contribuindo para a melhoria da qualidade da educação, proporcionando troca de experiências e saberes sobre questões ligadas ao cotidiano da sala de aula, em especial ao conteúdo de química.

Assim, acredita-se que o PIBID contribui para que a formação inicial não seja reducionista, mas, para que ofereça e desperte em cada um dos graduados e acadêmicos, professores, supervisores e coordenadores a necessidade de que o educador envolva-se constantemente em atividades de que possibilitem a formação continuada, melhorando assim seu papel de professor motivador.

\section{CONCLUSÕES}

Esta pesquisa nos permite compreender que o PIBID é um espaço que possibilita a integração entre a universidade a escola, oportunizando aos futuros professores o entendimento e a reflexão sobre a profissão docente e também sobre a realidade escolar, valorizando o espaço escolar como campo de experiência para a produção de novos conhecimentos durante sua formação.

O trabalho docente é complexo e exige a construção e integração de fatores que ultrapassam as relações mantidas no interior da sala de aula. Sendo assim, podemos dizer que o PIBID é uma ferramenta complementar na formação acadêmica e no desenvolvimento da prática metodológica, oportunizando o contato com teorias educacionais, permitindo a compreensão das relações concretas vividas no contexto educacional e no processo de ensino e aprendizagem, bem como na relação teoria e 
prática, aspectos importantes na formação do professor.

As atividades experimentais e demonstrativas elaboradas pelos bolsistas para pautar os conteúdos de química, deverão fazer parte da formação dos acadêmicos, professores em formação, permitindo uma melhor qualificação na sua futura atuação profissional. O PIBID-Química-UERR provavelmente colaborará para que os alunos de iniciação à docência vislumbrem que as dificuldades encontradas na escola pública atual são desafios com possibilidades de serem vencidos.
(Especialização em Ensino na Educação Básica) Educação e Ciências Humanas, Universidade Federal do Espírito Santo, Espírito Santo.

Santos, W. L. P. \& Schnetzler, R. P. 2010. Educação em química: compromisso com a cidadania. 4a ed. Unijuí, 150p.

Santos, W.L.P. 2007. Contextualização no ensino de ciências por meio de temas CTS em uma perspectiva crítica. Ciência \& Ensino. 1: 1-12.

Silva, M. G. L. \& Pinto, A. F. 2014. Reflexões do PIBID -Química da UFRN: Para Além da Iniciação à Docência. Quimica Nova na Escola 36(2): 101-107.

\section{REFERÊNCIAS BIBLIOGRÁFICAS}

Arroio, A., Honório, K.M., Mello, P.H., Weber, K.C. \& Silva, A.B.F. 2008. A prática docente na formação do pós-graduando em Química. Química Nova. 31 (7): 1888-1891.

Braibante, M.E.F. \& Wolmann, E.M. 2012. A Influência do PIBID na Formação dos Acadêmicos de Química. Química Nova na Escola. 34(4): 167-172.

Carvalho, A.M.P. \& Gil-Pérez, D. Formação de professores de ciências. São Paulo: Cortez, 2000.

Clímaco, J.C.T.S.; Neves, C.M.C. \& Lima, B.F.Z. 2012. Ações da Capes para a formação e a valorização dos professores da educação básica do Brasil e sua interação com a pós-graduação. Revista Brasileira de Pós-Graduação. 9(16): 181-209.

Echeverría, A. R. \& Zanon, L. B. 2010. Formação superior em química: práticas e fundamentos curriculares. Unijuí, Ijuí, 212p.

Guimarães, C.C. 2009. Experimentação no ensino de química: caminhos e descaminhos à aprendizagem significativa. Química Nova na Escola. 31: 198-202.

Lima, J. O. G. 2012. Perspectivas de Novas Metodologias no Ensino de Química. Revista Espaço Acadêmico 12 (136): 95-101.

Maldaner, O. A. 2013. A formação Inicial e Continuada de Professores de Química: professores/ pesquisadores. 4 ed. Ijuí: UNIJUÍ.

Pauletti, F. 2012. Entraves ao Ensino de Química: apontando meios para potencializar este ensino. Revista Amazônica de Ensino de Ciências. 5(8): 98107.

Paredes, G.G.O. \& Guimarães, O.M. 2012. Compreensões e Significados sobre o PIBID para a Melhoria da Formação de Professores de Biologia, Física e Química. Química Nova na Escola 34(4): 266-277.

Rosa, L. D. 2012. Aplicação de Metodologias Alternativas Para uma Aprendizagem Significativa no Ensino de química. 2012. Dissertação 